\title{
Spontaneous Intracranial Internal Carotid Artery Dissection Treated by Intra-arterial Thrombolysis and Superficial Temporal Artery-Middle Cerebral Artery Anastomosis in the Acute Stage -Case Report-
}

\author{
Hideki OGIWARA, Keiichirou MAEDA, Takayuki HARA, \\ Toshikazu KIMURA, and Hajime ABE
}

Department of Neurosurgery, Aizu Central Hospital, Aizuwakamatsu, Fukushima

\begin{abstract}
A 22-year-old man presented with sudden onset of right retro-orbital headache followed by left hemiparesis. Right carotid angiography demonstrated almost total occlusion of the intracranial internal carotid artery (ICA) and severe stenosis of the middle cerebral artery (MCA), presumably caused by arterial dissection. Local arterial injection of urokinase was performed 2 hours after onset. The ICA became patent, but the $M_{2}$ portion of the MCA was still occluded, and the left hemiparesis did not improve. Superficial temporal artery-MCA anastomosis was immediately performed. The left hemiparesis disappeared completely 6 days after this procedure. Angiography 2 weeks after the onset revealed occlusion of the ICA, and maintenance of blood flow to the right cerebral hemisphere via the anastomosis. Magnetic resonance imaging showed small infarcts in the right cerebral cortex. Repeat angiography after 5 months showed recanalization of the right ICA and the right MCA. Combination of thrombolytic therapy and bypass surgery may be a useful treatment option for patients with sudden occlusion of the intracranial artery caused by dissection.
\end{abstract}

Key words: intracranial internal carotid artery dissection, thrombolysis, superficial temporal artery-middle cerebral artery anastomosis

\section{Introduction}

Spontaneous intracranial arterial dissections are relatively uncommon and usually occur in the vertebral and basilar arteries. Dissection of the intracranial carotid artery has been recognized as a cause of ischemic stroke, especially in young adults, since 1990..$^{2,19-22,25)}$ The incidence and natural history of intracranial internal carotid artery (ICA) dissection remain unclear because few cases have been described. The prognosis for these patients is considered to be good in general, although massive cerebral infarct was reported in severe cases. $^{9-11,18,23,25)}$ Bypass surgery ${ }^{13,21)}$ or endovascular intervention ${ }^{4,5,15,24)}$ have been advocated as potential therapeutic options to reduce ischemic damage.

We treated a patient with intracranial carotid dissection using both intra-arterial thrombolysis

Received April 23, 2004; Accepted October 8, 2004 and superficial temporal artery-middle cerebral artery (STA-MCA) anastomosis. The infarct occurred in a limited field of the cerebral hemisphere and the outcome of the patient was good.

\section{Case Report}

A previously healthy 22-year-old man suffered sudden onset of right retro-orbital headache and presented to the emergency room 1 hour later. He had no history of recent trauma. On admission, he was drowsy and complained of moderate left hemiparesis and left hemihypesthesia. His eyes deviated to the right. His blood pressure was 110/64 mmHg.

Computed tomography (CT) showed no abnormalities. Cerebral angiography obtained 2 hours after the onset of symptoms demonstrated almost total occlusion of the right ICA and irregular string-like narrowing of the right MCA, indicating arterial 

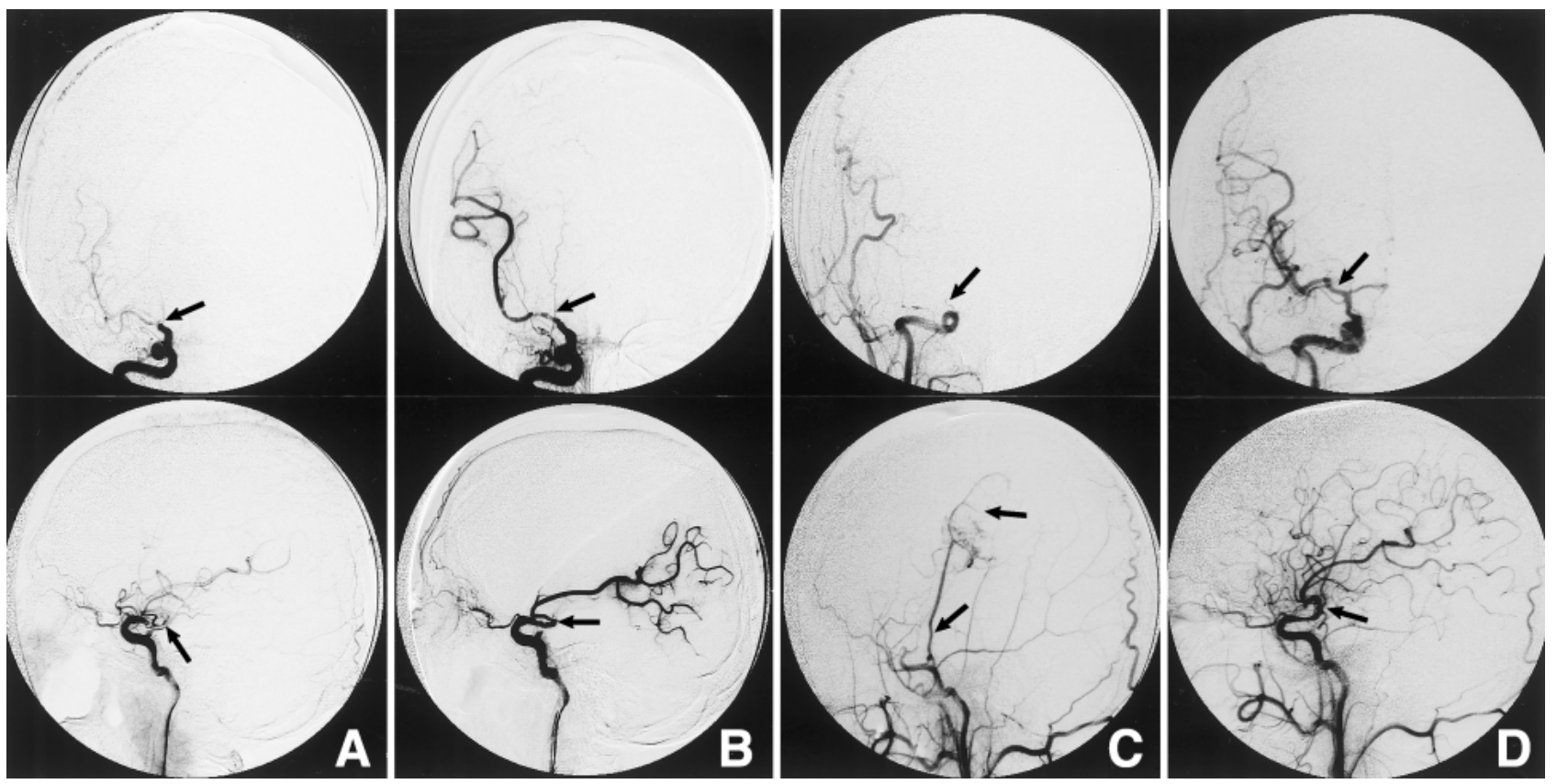

Fig. 1 A: Initial right carotid angiograms showing almost total occlusion of the distal end of the internal carotid artery (ICA) (arrow) and irregular string-like narrowing of the middle cerebral artery (MCA). B: Right carotid angiograms following thrombolysis 3 hours after the onset showing patency of the right ICA (arrow), and the $M_{1}$ and the inferior $M_{2}$ branches of the right MCA, but persistent occlusion of the superior $M_{2}$ branch. C: Right carotid angiograms 14 days after the onset showing total occlusion of the distal end of the ICA (arrow). The superficial temporal artery-MCA anastomosis (arrow) was patent, supplying blood mainly to the motor cortex of the right cerebral hemisphere. D: Right carotid angiograms after 5 months showing recanalization of the right ICA (arrow) and the right MCA, with slight stenosis of the $M_{1}$.

dissection (Fig. 1A). Local intra-arterial thrombolysis was performed with continuous infusion of 420,000 units of urokinase. Post-thrombolysis angiography 3 hours after the onset showed that the right ICA, and the $\mathrm{M}_{1}$ and the inferior $\mathrm{M}_{2}$ branches of the right MCA were patent, but the superior $\mathrm{M}_{2}$ branch of the right MCA was still occluded (Fig. 1B). His left hemiparesis persisted. CT after the thrombolytic therapy still demonstrated no ischemic change and there was no hemorrhage. STA-MCA anastomosis was performed to improve the vascular flow in the superior $\mathrm{M}_{2}$ branch of the right MCA. The STA was anastomosed to the cortical artery of the right motor area 7 hours after onset.

The day after the operation, the patient became alert, and his left hemiparesis ameliorated. CT showed a small infarct in the peripheral territory of the right MCA without hemorrhage. Anticoagulation therapy with warfarin was started. His hemiparesis resolved completely on the 6th day after admission. Magnetic resonance imaging disclosed small infarcts in the right frontal cortical area and

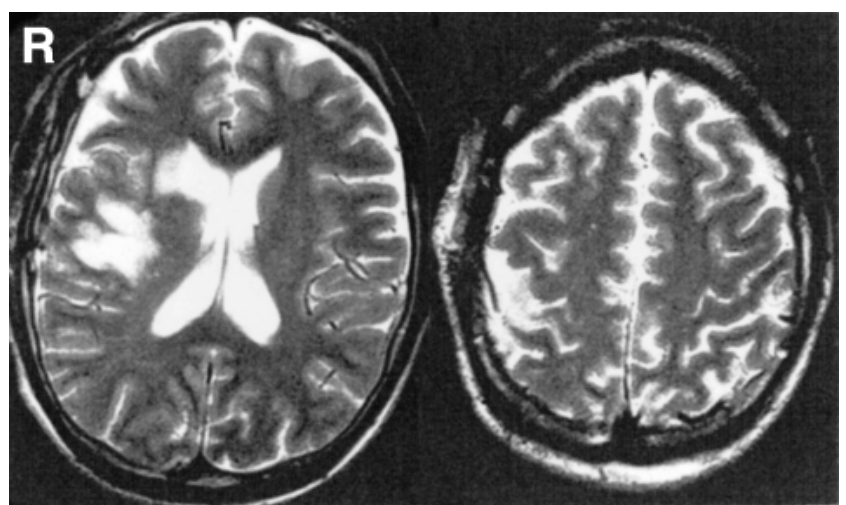

Fig. $2 \mathrm{~T}_{2}$-weighted magnetic resonance images obtained on the 6th day demonstrating small infarcts in the right frontal cortical area and the right basal ganglia.

the right basal ganglia (Fig. 2). Repeat angiography on the 14th day unexpectedly demonstrated complete occlusion of the ICA. The STA-MCA anas- 
tomosis was patent, supplying blood mainly to the motor cortex of the right cerebral hemisphere (Fig. 1C).

The patient was discharged on the 30th day after admission with only mild hypesthesia of his left hand. Repeat angiography after 5 months showed recanalization of the right ICA and the right MCA, with slight stenosis of the right $\mathrm{M}_{1}$ (Fig. 1D). The patient received antiplatelet therapy with ticlopidine and remained asymptomatic at the last follow-up examination, 8 months after onset.

\section{Discussion}

Local intra-arterial thrombolysis improves the outcome in patients with embolic stroke, if performed within several hours of the onset. ${ }^{6,26)}$ Thrombolysis treatment has also been successful in patients with arterial occlusion caused by dissection. ${ }^{4,5,15,24)}$ The thrombolytic agent acts on clots both in the true lumen and the false lumen of the dissecting vessel, resulting in reduced stenosis. However, arterial dissection is known to cause subarachnoid hemorrhage even if the first manifestation is cerebral ischemia. Therefore, thrombolytic therapy has the potential to aggravate the risk of subarachnoid hemorrhage. ${ }^{9,11)}$ The dosage of the thrombolytic agent must be cautiously selected. There is also a risk of intracerebral hemorrhage from reperfusion of occluded vessels after thrombolysis. Early ischemic changes on CT, delayed treatment, advanced age of the patients (aged $>70$ years), and hypertension are all risk factors for intracerebral hematoma formation after intravenous thrombolysis with recombinant tissue plasminogen activator. ${ }^{3,12,14,16,27)}$ To reduce the risk of hemorrhagic transformation, we performed thrombolysis (2 hours after the onset) and STA-MCA anastomosis (7 hours after the onset) as soon as possible, confirmed the absence of early ischemic changes on CT before each treatment, and maintained the systolic blood pressure under 140 $\mathrm{mmHg}$ and the diastolic pressure under $80 \mathrm{mmHg}$.

Re-occlusion or re-stenosis may occur in the dissecting vessel after thrombolysis as in the present case. ${ }^{13)}$ Furthermore, the clot generated in the dissecting artery may occlude the distal artery. ${ }^{1)}$ Therefore, the blood flow of the affected vascular territory may become unstable after arterial dissection. Under such conditions, STA-MCA anastomosis can help to maintain peripheral blood perfusion and prevent massive infarction, as in cases of MCA dissection. ${ }^{13,21)}$

In this case, dissection started just distal to the bifurcation of the anterior choroidal artery (AchoA). Thrombolysis at this location did not result in occlusion of AchoA or posterior communicating artery. The extent of dissected ICA can be related to the prognosis of the thrombolysis.

Recently, stenting was shown to be safe and efficient for the treatment of intracranial atherosclerotic arterial stenosis, and iatrogenic dissection of the basilar artery. ${ }^{7,8,17)}$ The introduction of a new generation of devices has made the use of stents in the intracranial vasculature more feasible and safe. Stenting would also be useful for reducing re-stenosis of the dissecting vessel.

Thrombolytic therapy can be started quickly compared with surgical procedures and can help to reduce the infarct size. The advantage of bypass surgery is that peripheral perfusion is maintained even after occlusion of the affected intracranial ICA or MCA. The combination of both therapies may improve the prognosis for patients with intracranial arterial dissection.

\section{References}

1) Bogousslavasky J, Despland PA, Regli F: Spontaneous carotid dissection with acute stroke. Arch Neurol 44: 137-140, 1987

2) Chaves C, Estol C, Esnaola MM, Gorson K, O’Donoghue M, De Witt LD, Caplan LR: Spontaneous intracranial internal carotid artery dissection: report of 10 patients. Arch Neurol 59: 977-981, 2002

3) del Zoppo GJ, Poeck K, Pessin MS, Wolpert SM, Furlan AJ, Ferbert A, Alberts MJ, Zivin JA, Wechsler L, Busse O: Recombinant tissue plasminogen activator in acute thrombotic and embolic stroke. Ann Neurol 32: 78-86, 1992

4) Findlay JM, Ashforth R, Dean N: "Malignant", carotid artery dissection. Can J Neurol Sci 29: 378-385, 2002

5) Fu Y, Komiyama M, Inoue T, Ohata K, Matsuoka Y, Hakuba A: [A case of middle cerebral artery occlusion caused by dissecting aneurysm]. No Shinkei Geka 24: 955-959, 1996 (Jpn, with Eng abstract)

6) Furlan A, Higashida R, Wechsler L, Gent M, Rowley H, Kase C, Pessin M, Ahuja A, Callahan F, Clark WM, Silver FL, Rivera F: Intra-arterial prourokinase for acute ischemic stroke. The PROACT II study: a randomized controlled trial. Prolyse in Acute Cerebral Thromboembolism. JAMA 282: 2003-2011, 1999

7) Gomez CR, Misra VK, Campbell MS, Soto RD: Elective stenting of symptomatic middle cerebral artery stenosis. AJNR Am J Neuroradiol 21: 971-973, 2000

8) Gomez CR, Misra VK, Liu MW, Wadlington VR, Terry JB, Tulyapronchote R, Campbell MS: Elective stenting of symptomatic basilar artery stenosis. Stroke 31: 95-99, 2000

9) Grosman H, Fornasier VL, Bonder D, Livingston KE, Platts ME: Dissecting aneurysm of the cerebral 
arteries: case report. J Neurosurg 53: 693-697, 1980

10) Hegedus K: Dissecting intracranial aneurysm. Arch Psychiatr Nervenkr 232: 25-32, 1982

11) Hochberg FH, Bean C, Fisher M, Roberson GH: Stroke in a 15-year-old girl secondary to terminal carotid dissection. Neurology 25: 725-729, 1975

12) Kano T, Katayama Y, Tejima E, Lo EH: Hemorrhagic transformation after fibrinolytic therapy with tissue plasminogen activator in a rat thromboembolic model of stroke. Brain Res 854: 245-248, 2000

13) Kitani R, Itouji $T$, Noda $Y$, Kimura M, Uchida S: Dissecting aneurysms of the anterior circle of Willis arteries: report of two cases. J Neurosurg 67: 296-300, 1987

14) Larrue V, von Kummer RR, Muller A, Bluhmki E: Risk factors for severe hemorrhagic transformation in ischemic stroke patients treated with recombinant tissue plasminogen activator: a secondary analysis of the European-Australasian Acute Stroke Study (ECASS II). Stroke 32: 438-441, 2001

15) Leistner S, Hartmann A, Marx P, Koennecke HC: Successful thrombolytic treatment of intracranial carotid occlusion due to dissection. Eur Neurol 45: 284-285, 2001

16) Levy DE, Brott TG, Haley EC Jr, Marler JR, Sheppard GL, Barsan W, Broderick JP: Factors related to intracranial hematoma formation in patients receiving tissue-type plasminogen activator for acute ischemic stroke. Stroke 25: 291-297, 1994

17) Malek AM, Higashida RT, Halbach VV, Phatouros CC, Meyers PM, Dowd CF: Tandem intracranial stent deployment for treatment of an iatrogenic, flow-limiting, basilar artery dissection: technical case report. Neurosurgery 45: 919-924, 1999

18) Manz HJ, Vester J, Lavenstein B: Dissecting aneurysm of cerebral arteries in childhood and adolescence: case report and literature review of 20 cases. Virchows Arch A Pathol Anat Histol 384: 325-335, 1979

19) Mizutani T: Middle cerebral artery dissecting aneurysm with persistent patent pseudolumen. J Neurosurg 84: 267-268, 1996

20) Ohkuma H, Suzuki S, Ogane K: Dissecting aneurysms of intracranial carotid circulation. Stroke 33: 941-947, 2002

21) Park-Matsumoto YC, Tazawa T: Transcranial bypass for spontaneous intracranial carotid artery dissection: a case report. Angiology 51: 335-341, 2000

22) Pelkonen O, Tikkakoski T, Leinonen S, Pyhtinen J, Sotaniemi K: Intracranial arterial dissection. Neuroradiology 40: 442-447, 1998

23) Pessin MS, Adelman LS, Barbas NR: Spontaneous intracranial carotid artery dissection. Stroke 20: 1100-1103, 1989

24) Sampognaro G, Turgut T, Conners JJ, White C, Collins T, Ramee SR: Intra-arterial thrombolysis in a patient presenting with an ischemic stroke due to spontaneous internal carotid artery dissection. Catheter Cardiovasc Interv 48: 312-315, 1999

25) Sharif AA, Remley KB, Clark HB: Middle cerebral artery dissection: a clinico-pathologic study. Neurology 45: 1929-1931, 1995

26) Tarr R, Taylor CI, Selman WR, Lewin JS, Landis D: Good clinical outcome in a patient with a large CT scan hypodensity treated with intra-arterial urokinase after an embolic stroke. Neurology 47: 1076-1078, 1996

27) Tejima E, Katayama Y, Suzuki Y, Kano T, Lo EH: Hemorrhagic transformation after fibrinolysis with tissue plasminogen activator: evaluation of role of hypertension with rat thromboembolic stroke model. Stroke 32: 1336-1340, 2001

Address reprint requests to: H. Ogiwara, M.D., Genome Science Division, Research Center for Advanced Science and Technology, The University of Tokyo, 4-6-1 Komaba, Meguro-ku, Tokyo 153-8904, Japan. e-mail: ogiwara-h@genome.rcast.u-tokyo.ac.jp 